\title{
8
}

\section{Action Research for Instructional Improvement: Using Data to Enhance Student Learning at Your Institution}

\author{
Constance E. Cook, Mary Wright, Christopher O'Neal \\ University of Michigan
}

Action research is a powerful tool that can be used by teaching centers to improve teaching and learning. This chapter describes an action research project conducted at the Center for Research on Learning and Teaching at the University of Michigan. The project concerns retention and attrition in science gateway courses, with particular attention given to the role of the teaching assistant. This chapter concludes with a discussion of six principles for teaching center staff who wish to conduct their own action research projects.

T he role of most teaching centers at universities across the country is to improve teaching and student learning by creating a culture of pedagogical excellence, responding to instructors' needs, and advancing teaching and learning through new initiatives (Sorcinelli, Austin, Eddy, \& Beach, 2006). In this chapter, we document one useful approach to enhance student learning through a methodology called action research. Coined by psychologist Kurt Lewin (1948/1997), action research (or action inquiry) generally refers to any research that is used as the basis and motivation for reform. Sorcinelli et al., in their discussion of the "evolution" of faculty development, describe a move from the 1950's and 1960's Age of the Scholar (emphasizing support for faculty research) to today's Age of the Learner (supporting effective pedagogy and scholarship of teaching and learning) and tomorrow's Age of the Network, in which faculty and developer roles expand and collaboration becomes key to success. An action research approach is ideally situated for 
contemporary faculty development activities as it emphasizes collaboration and supports student learning through data-driven investigation.

The Center for Research on Learning and Teaching (CRLT) at the University of Michigan illustrates the path of one teaching center to an action research approach. CRLT was established in 1962, and as its name implies, research was its primary focus for its first decades. In the 1980s, CRLT's emphasis moved to a mix of research and service to faculty, and by the 1990s, its focus was mostly on programmatic faculty development in response to the provost's mandate that teaching improvement was important and faculty development was the way to achieve it. This emphasis implies that there was no research at all, which was not the case; evaluation research was a regular part of the service CRLT provided. What the center rarely did, however, was initiate major research projects that went beyond investigation of a single course or curriculum.

In this new age, CRLT has broadened its own focus to embrace more of its research roots. We augment our faculty development programs with periodic research projects, and the research improves our programming. Our research usually is done at the request of academic leaders, especially deans, and it informs and improves the services we provide for them, as well as instructors' practice, curricula, and institutional cultures. This type of research is a form of inquiry termed action research, and it is a powerful tool by which teaching centers can improve instruction.

Lewin (1948/1997) described action research as a process, or a "spiral of steps each of which is composed of a cycle of planning, action, and fact-finding about the result of the action" (p. 146). Organizational action research is not new to higher education. Using evaluation research to inform institutional change in higher education has been around since the master planning movement of the 1960s (Halstead, 1974; St. John, McKinncy, \& Tuttle, in press). Since that time, action research has been used as a democratization method by which various constituencies can be brought into the change process (Armstrong \& Moore, 2004; Benson \& Harkavy, 1996; Park, 1999), an experiential tool to engage learners (Geltner, 1993; Krogh, 2001; Zuelke \& Nichols, 1995), and a process to conduct classroom rescarch (Cross \& Steadman, 1996; Schön, 1983, 1987). There are many variants of action rescarch, such as participatory action research, cooperative inquiry, empowerment research, community-based rescarch, and feminist rescarch (Reason, 1999; Small, 1995; Strand, Marullo, Cutforth, Stocker, \& Donohue, 2003).

There are several reasons why teaching centers are idcally suited to do action research. First, their institutional perspective is advantageous for this type of inquiry. While the organizational structure of teaching centers varies 
widely, most are central units with a broad mandate for change and the capacity to have an institution-wide perspective, not one rooted in a single school or college (Sorcinelli et al., 2006; Wright \& O'Neill, 1995). This perspective can inform directors about the issues of concern to academic administration. Furthermore, the institutional position of a teaching center means that the staff know what data are available and are likely to be able to get permission to access it. Additionally, teaching centers, particularly larger ones, often are involved in evaluation projects, which means that data are near at hand and evaluation of action plans is efficacious (Wright \& O'Neill, 1995).

Second, teaching center professional staff typically have the academic and professional backgrounds needed to conduct effective action research. Many have doctorates (Gillespic, 2001), and the action researcher's role as "catalyst" or "resource" (rather than "expert") parallels many consultants' approaches to their professional practice (Brinko, 1997; Stringer, 1999).

Finally, teaching centers are service organizations and their mission is to implement good ideas for improving teaching and learning on campus. When they analyze data and conclude that improvement is necessary and action needs to be taken, they already are positioned to use the data to implement an action plan, then evaluate its results. They can begin work on improving programs and services right away and are connected to campus faculty who are likely to agree to be early adopters of teaching innovations.

The most common type of teaching center-based action research is the solicitation of student opinions about a course through Small Group Instructional Diagnosis or evaluation and the use of that feedback to improve the course (Nyquist \& Wulff, 1988; Seldin, 1997). However, action research that extends beyond the individual classroom appears to be rare. Key exceptions include action research on graduate students' career goals in order to plan professional development programs (Bellows \& Weissinger, 2005), use of student feedback to assess and revise departmental curricula (Black, 1998), initiatives to enhance students' writing and study skills (Zuber-Skerritt, 1992), and other projects that fall under the heading of assessment of student learning or the scholarship of teaching and kearning. Additionally, the Center for Instructional Development and Research at the University of Washington has collected data on departments, such as grade distributions, class size, student ratings, and TA training, and has used that data to help departments identify needs and effect improvements (J. Nyquist, personal communication, October 1996).

In spite of the many advantages that teaching centers have in conducting action research, these centers also face special challenges. Because they are service units, it is hard for professional staff to find time to do rescarch that involves gathering data. Also, laching center budgets are dependent on the 
decisions of academic administrators, so it is important to be collaborative and helpful, not adversarial and critical. Furthermore, teaching center programs and services are rarely mandatory. Faculty use them because of their perceived value, so it is vital for a center to maintain a positive image on campus as a place that supports faculty and the academic units. To engage in behavior that alienates it from its faculty constituency would be self-defeating. These issues echo questions raised in action research that address politically charged problems and engagement of multiple constituencies (Polanyi \& Cockburn, 2003). Other questions raised in the action research literature that are relevant to teaching center staff who conduct such inquiries include

- How do researchers manage tensions among their multiple roles as change agent, researcher, consultant, ally, and evaluator (Chesler, 1990; Elden, 1981)?

- How do researchers manage tensions between themselves and organization members about the interpretation of research, needed interventions, and how or whether to communicate results (Bishop, 1994; Greenwood \& Levin, 1998; Israel, Schurman, \& Hugentobler, 1992)?

Despite these challenges, teaching centers have much to gain from engaging in action research. In the following sections, to describe what we have learned about how to effectively conduct action research in a teaching center, we first present one case study to illustrate the process. We begin by situating CRLT's action research project within the national problem of retention in the sciences. We then describe the steps we took to engage in the action research project on the local level; that is, our work with three large science departments at the University of Michigan. Action research typically involves three key steps: planning, acting on findings, and reflection (Lewin, 1948/1997; Zuber-Skerritt, 1992), and we note our process in each of these stages. Finally, based on our experiences and the challenges noted earlier in the action research literature, we recommend six principles for conducting effective action research in a teaching center. Table 8.1 integrates the action research stages, our recommendations for teaching centers that wish to conduct action research stages, and what CRLT did in its study of undergraduate attrition in the sciences.

\section{The National Problem}

Nationally, retention in science has become a matter of real importance as educational institutions try to slow the sizable flow of undergraduates out of sci- 
entific fields (Campbell, Jolly, Hoey, \& Perlman, 2002; National Science Foundation, 2003; Strenta, Elliot, Adair, Matier, \& Scott, 1994). For two decades, the National Science Foundation (NSF) has been especially active in addressing attrition through a series of grants, workshops, publications, conferences, and other interventions designed to improve science retention at US universities. In 2004, the Government Accounting Office reported that NSF and 12 other federal agencies spent $\$ 2.8$ billion on programs intended to increase the number of students pursuing studies in science, technology, engineering, and

TABLE 8.1

CRLT Action Research Stages, Principles, and Steps

\begin{tabular}{|c|c|c|}
\hline $\begin{array}{c}\text { Action Research } \\
\text { Stage }\end{array}$ & $\begin{array}{l}\text { Principles to Guide Action } \\
\text { Research in a Teaching Center }\end{array}$ & $\begin{array}{l}\text { What CRLT Did in the Study of } \\
\text { Student Attrition in the Sciences }\end{array}$ \\
\hline \multirow{3}{*}{ Planning } & $\begin{array}{l}\text { 1) Focus on research that is central } \\
\text { to a teaching center's mission }\end{array}$ & $\begin{array}{l}\text { 1) Undertook a study central to } \\
\text { CRLT's mission of promoting a } \\
\text { university culture that values } \\
\text { teaching and supports learning } \\
\text { environments in which diverse } \\
\text { students can excel }\end{array}$ \\
\hline & $\begin{array}{l}\text { 2) Shape the action research project } \\
\text { so it answers questions of national } \\
\text { importance while also being } \\
\text { relevant and specific to local } \\
\text { problems }\end{array}$ & $\begin{array}{l}\text { 2) Designed a study that responded } \\
\text { to local needs (task force report and } \\
\text { departments' goals), as well the } \\
\text { national problem of retention in the } \\
\text { sciences }\end{array}$ \\
\hline & $\begin{array}{l}\text { 3) Obtain the buy-in of both the } \\
\text { administrators motivating the } \\
\text { study and the faculty and units that } \\
\text { are the subject of study }\end{array}$ & $\begin{array}{l}\text { 3) Met with dean and departments } \\
\text { to gain support for study }\end{array}$ \\
\hline \multirow[t]{2}{*}{ Acting } & $\begin{array}{l}\text { 4) Communicate the results of the } \\
\text { study in a way that generates sup- } \\
\text { port for improvements without } \\
\text { alienating the individual units or } \\
\text { people who will have to implement } \\
\text { those improvements }\end{array}$ & $\begin{array}{l}\text { 4) Presented results of study to } \\
\text { departments and engaged in } \\
\text { collaborative strategizing }\end{array}$ \\
\hline & $\begin{array}{l}\text { 5) Enhance credibility for the project } \\
\text { by modifying the teaching center's } \\
\text { own programs and practice when } \\
\text { research findings indicate a need }\end{array}$ & $\begin{array}{l}\text { 5) Made improvements to CRLT's } \\
\text { TA training programs }\end{array}$ \\
\hline Reflécting & $\begin{array}{l}\text { 6) Stay involved in the change } \\
\text { process after research is complete to } \\
\text { facilitate, guide, and evaluate } \\
\text { reforms }\end{array}$ & $\begin{array}{l}\text { 6) Developed action research prin- } \\
\text { ciples, worked with departments to } \\
\text { enact changes, and planned for } \\
\text { future evaluation of reforms }\end{array}$ \\
\hline
\end{tabular}


mathematics (Selingo, 2005). Attrition in the sciences is especially problematic in the undergraduate years because approximately $40 \%$ of the students who come to college intending to major in the sciences ultimately decide to major in something else (Astin \& Astin, 1993; Seymour \& Hewitt, 1997; Strenta, et al.). Many of those who leave the sciences are capable students with the aptitude to do well in science (Montgomery \& Groat, 1998; Seymour \& Hewitt, 1997; Tobias, 1990), and the attrition problem is particularly acute for women and people of color (Astin \& Astin, 1993; Holstrom, Gaddy, Van Horne, \& Zimmerman, 1997; Seymour, 2001; Xie \& Shauman, 2003).

Not much literature exists on the role of teaching assistants in attrition or retention, and the literature that does exist reports that the TA is not an important factor (Seymour \& Hewitt, 1997). Nonetheless, most undergraduate science, technology, engineering, and math majors are educated at research universities that employ large numbers of TAs in science courses (National Science Board, 2004). Students in the sciences often depend more on TAs to help them to learn basic concepts than do students in disciplines outside the sciences, especially because students find it more difficult to learn from science faculty and also because science faculty delegate more teaching responsibility to TAs (Seymour \& Hewitt, 1997; Seymour, Melton, Wiese \& Pedersen-Gallegos, 2005).

\section{CRLT Research Project}

The CRLT action research project grew out of the experience of the University of Michigan Task Force on Testing and Training Prospective Graduate Student Instructors (Cook et al., 2002). The task force was composed of a group of academic leaders from the major undergraduate schools at the University of Michigan: the College of Literature, Science, and the Arts, and the College of Engineering. It was convened to consider how to improve the training of TAs, particularly those who were teaching in the sciences. Lacking relevant data, the task force suggested that CRLT begin an action research project to gather relevant data for future decision-making.

\section{Planning the Action Research Project}

Attrition in the sciences is especially likely in the first two years of college (Seymour \& Hewitt, 1997), so CRLT's research focused on the part of the leaky pipeline known as the gateway course. The gateway course is the initial college course in the sciences taken by a first- or second-year student who has studied science in high school and expects to major in science in college. After 
the institutional review board approved the study, CRLT surveyed more than 3,600 undergraduate students in the gateway courses for prospective science majors. The survey was distributed immediately following the completion of the survey course, and questions concerned students' intention to major in the sciences both before and after they enrolled in the course, as well as reasons for this decision and their views on their TAs. The high response rate $(73 \%)$ is likely attributable to a small set of prizes offered to students taking the survey. To supplement survey data, we gathered information from the registrar on student grades in these classes and any additional courses they took in the sciences in two subsequent semesters. We also collected data on the science TAs: demographic characteristics, number of terms as University of Michigan graduate students and as TAs, undergraduate English language background, and end-of-term student ratings. Additionally, we examined the TA training programs in each of the departments.

\section{Acting on Research Findings}

This project generated three main findings that were especially relevant to the task force's initial questions.

- Most TAs in Michigan's science departments performed very well. Only a very small percentage of TAs could be classified as "problematic."

- Lab climate was one of the most important factors influencing students' plans to stay in or leave the sciences. Other factors that played a role in their decisions were their course grades, their math grades, and what they learned about careers.

- Retention of students in Michigan science programs was high, but still worrisome when considered in the long term, especially for female students.

This research project eventually led to reforms in the training of science TAs at the University of Michigan. The research findings were presented to chairs in the three departments surveyed, and CRLT staff collaboratively strategized with them on implications for their TA training programs and curricula. As a result of these discussions, two departments are revising their introductory courses significantly, two departments are implementing new evaluation and support systems for TAs (one department already had an effective system in place), and all three departments developed greater awareness of the impact of TAs on student performance and retention. We have recently initiated a follow-up study in one of the departments to assess the impact of their TA training and course reforms. 


\section{Reflecling}

CRLT was a constant partner in this change and continues to be active in helping departments institute and evaluate these reforms. However, like much action research, this project was politically charged and required careful navigation by the center in order to emerge from the research project with allies in the departments instead of enemies. In the following section, we discuss six principles that we feel were key to our project's success.

Principle 1: Focus on research that is central to a teaching center's mission. Teaching centers are busy, often overcommitted, places. Because of their unique position on campus as an interface between students, faculty, departments, and administrators, they are also susceptible to mission creep. For a center to commit resources and staff to an action research project, that initiative must support a center's core mission. For CRLT, our central purpose is to "promote a University culture that values and rewards teaching, respects and supports individual differences among learners, and encourages the creation of learning environments in which diverse students can learn and excel."

This action research project on the TA's role in attrition and retention in the sciences was an excellent fit with this mission. While the research was enormously time-consuming for CRLT, we saw it as a project that could have a great impact on teaching and learning, especially through better TA training, and it even would support the center's multicultural mission by positively impacting science enrollments of underrepresented groups.

Principle 2: Shape the action research project so it answers questions of national importance while also being relevant and specific to local problems. This principle may seem counterintuitive to centers struggling to improve teaching and learning on their own campuses. However, there are a number of reasons to focus on national issues. First, the more teaching centers are connected to reform at the national level, the more they will be seen as legitimate players in shaping higher education. When tasked with investigating TA training in the sciences at the university, CRLT decided to focus on science student retention as one key measure of TA effectiveness. This decision has added prestige and exposure for the center through presentations of the research at national forums. That exposure has led to more willingness to engage with the center on these issues at the campus level. Second, faculty are immersed in their own departmental cultures and attuned to issues that are highlighted by their disciplines at the national level (Gouldner, 1957). By choosing to focus on student retention in the sciences as one measure of TA effectiveness, CRLT was focusing on an issue of real concern in the sciences. Department administrators, previously unexcited about a project on TA training, became very engaged with issues of student retention. 
Principle 3: Obtain the buy-in of both the administrators motivating the study and the faculty and units that are the subject of study. Because the university's task force highlighted the dearth of data to inform its report, the need for a research project on the role of TAs was clear (Cook et al., 2002). That catalyst was very helpful in paving the way for the CRLT research project. Furthermore, we were fortunate to have a new dean in Michigan's liberal arts college who was eager to improve teaching and learning and who was willing to put his authority behind actions designed to accomplish those objectives. He is not a scientist and wanted to know more about the science instruction provided by his college, so he saw this research project as a way to inform himself. It is important to note that without his interest and support, the research could not have gone forward.

However, for this research project to succeed, the support of the dean and each of the chairs and associate chairs from the involved departments was necessary. We decided to meet individually with each department's administrators to stress that the survey data analysis on their departments was going to each of them directly (rather than going to the dean first) so they could decide independently what improvements and interventions might be helpful. Not surprisingly, some individual instructors and departments were not eager to have us collect data on their students and TAs. A fourth department opted out of the study altogether. We should note that due to the success of this initial research project, the dean is now working with the chair of this department to do a similar study of its TAs.

Once general buy-in to the project was achieved, CRLT worked with key faculty in the departments to determine the relevant gateway courses for study and agree on the research design. We worked with the departments until we gained their trust and finally agreed on specific courses and specific protocols for the research. This step was crucial for performing the research, but it also helped prime the departments to act on the research findings.

Principle 4: Communicate the results of the study in a way that generates support for improvements without alienating the individual units or people who will have to implement those improvements. Although the dean had supported the study and the department chairs and faculty helped to create the questionnaire, only CRLT was involved in data analysis and decisions about how to report the results. We began by giving aggregate results to the dean and associate deans. In these reports we did not release specifics about the strengths and weaknesses of the departments. Next, we met individually with representatives from each department and presented both aggregate results and their specific departmental results. Strengths were emphasized and weaknesses candidly discussed, along with our suggestions for improvement. This 
respect for the authority of the department chairs helped to create a safe space for the chairs to initiate their own changes to TA training. Toward the end of the action research project, the dean asked about the departmental data and wanted information about the receptivity of the departments to curricular reform and TA training improvements. In our communications to the dean we emphasized the responsiveness of the departments and the substantial investment in training and curricular reform being undertaken there (one department allocated more than $\$ 250,000$ to the reforms suggested by our study).

Principle 5: Enhance credibility for the project by modifying the teaching center's own programs and practice when research findings indicate a need. Although many of the implications of our research fell within the purview of the science departments, CRLT also made a commitment to examining its own TA training programs. Our survey data showed that a special concern for undergraduates was communication with the TA, and student communication problems were named for both English-educated and non-English-educated TAs. First, we presented aggregate results to the university's English Language Institute, which together with CRLT, helps coordinate the training for new TAs educated abroad in a non-English medium. Many of the international TAs communicated very well, thanks to a variety of factors: careful screening of graduate students during the admissions process, workshops and courses offered by the English Language Institute and CRLT, and more rigorous testing of TAs' English classroom competency before they were assigned to the classroom. However, at the meeting we were able to strategize about how to enhance the training even further, such as by creating stronger early feedback and support systems for TAs after they enter the classroom.

Second, we focused on CRLT's training program for all TAs. Prior to the initiation of the study, recommendations of the Task Force on Testing and Training Prospective Graduate Student Instructors included two improvements to enhance the communication skills of all TAs, domestic and international (Cook et al., 2002). The first improvement was an individual practice teaching session (sometimes called micro-teaching) for every TA who attended the CRLT's central orientation. For two hours, all the TAs were divided into groups of six, each group with a trained instructional consultant. Each TA presented to the group a five-minute lesson in his or her own field and then received feedback on his or her teaching from the consultant and other TAs. Prior to the study, this portion of CRLT's TA orientation was optional, but findings of our research study confirmed the necessity of making this experience mandatory for all attendees. Given the hundreds of TAs who attend the University of Michigan TA orientations, this was a labor-intensive 
initiative, but the TAs reported it was the best part of the orientation and made them more confident as they began teaching classes. We were then able to recommend this practice to departments that hold their own TA training programs.

The second improvement to orientation was the addition of a one-hour interactive session on communication strategies. It describes and models ways to organize classes, use visual aids, and create interactivity among students. It also presents information about Michigan undergraduates in terms of academic background, social background, variations in learning styles, and patterns of intellectual development, to give TAs a good sense of the extent of diversity they will find in the classroom. Many TA developers know that because orientation programs have limited time, decisions about what to include in these programs can be difficult. However, because of the study's findings on TA undergraduate communication, we confirmed that this was a highly valuable part of the orientation that should be maintained.

Indeed, a follow-up formal evaluation of these elements in CRLT's TA evaluation confirmed that practice teaching and the session on communication strategies were valuable additions. Respondents reported that the sessions had a favorable impact on their sense of preparation for teaching at the university and their abilities to give effective presentations, teach a diverse group of students, create a positive classroom climate, use active learning methods, plan a lesson, and give feedback to students about what they are learning.

Principle 6: Stay involved in the change process after research is complete to facilitate, guide, and cvaluate reforms. Although all the science departments had well-established TA training programs separate from CRLT's own orientation, it was clear from the student survey responses that there was considerable variation between departments in the effectiveness of their students' learning experiences. Students had rated some departments' TAs highly and qualitative comments did not suggest that there be substantial changes in training. For other departments, the message was less favorable. Students especially criticized some TAs for poor communication skills and unclear or problematic grading systems. CRLT offered to provide the new practice teaching and communications modules for TAs to future departmental training programs, but it was important to find interventions that would improve instruction during the upcoming fall term.

To supplement their own training, two of the departments decided to initiate an early evaluation of TAs, asking students to fill out instructor ratings early in the semester so that problematic instructors could be identified quickly and the departments, along with CRLT staff, could offer support to 
those TAs and help them improve their teaching over the course of the semester. One department went so far as to arrange a follow-up training session for all TAs during one day of fall break so that all new instructors, not just those identified as problematic, could receive additional training. Another department arranged to have graduate student mentors, or advanced TAs hired to assist with TA development in the departments, consult with TAs who were struggling.

Based on the data from the survey of students, two departments determined that the problems with gateway courses went deeper than TA instruction and could be attributed to the nature of the courses themselves. One of those departments immediately embarked on a costly and time-consuming curricular reform effort that involved multiple instructors and all of its gateway courses. Another department has recently begun the effort to revise and improve its course offerings.

As noted by Lewin (1948/1997), a complete action research cycle involves not only action but also "fact-finding about the result of the action" (p. 146). For the interventions in all three departments, CRLT provided assistance; for example, overseeing some of the early evaluation, offering instruction at the follow-up training sessions, and providing benchmark data for the course revisions. A good action research project involves evaluation of the changes, and that, too, will be a CRLT responsibility.

\section{Conclusion}

At CRLT, we learned a great deal from our action research. We learned that our own TA orientation could be improved, and we had the data to guide that improvement process. We learned that the dean and his department chairs are eager to improve instruction and welcome data that offer advice about how to do so. We also learned that our offers of assistance with the interventions were as important as the data. The departments lack the capacity to initiate all these changes on their own without assistance. So we provided some of the staffing for the reform efforts. Perhaps the biggest lesson for us at CRLT was the power of data. We operate in a university that prides itself on research excellence, and we found that our carefully designed research project, producing high-quality data, was an effective way to get the attention of faculty and administrators and accomplish teaching improvement objectives. 


\section{References}

Armstrong, F., \& Moore, M. (2004). Action research: Developing inclusive practice and transforming cultures. In F. Armstrong \& M. Moore (Eds.), Action research for inclusive education: Changing places, changing practices, changing minds (pp. 1-16). London, England: RoutledgeFalmer.

Astin, A.W., \& Astin, H.S. (1993). Undergraduate science education: The impact of different college environments on the educational pipeline in the sciences. Los Angeles, CA: University of California-Los Angeles, Higher Education Research Institute.

Bellows, L., \& Weissinger, E. (2005). Assessing the academic and professional development needs of graduate students. In S. Chadwick-Blossey \& D. R. Robertson (Eds.), To improve the academy: Vol. 23. Resources for faculty, instructional, and organizational development (pp. 267-283). Bolton, MA: Anker.

Benson, L., \& Harkavy, I. (1996, June). Communal participatory action research as a strategy for improving universities and the social sciences: Penn's work with the West Philadelphia Improvement Corps as a case study. Educational Policy, 10(2), 202-222.

Bishop, R. (1994). Initiating empowering research. New Zealand Journal of Educational Studies, 29(1), 175-188.

Black, B. (1998). Using the SGID method for a variety of purposes. In M. Kaplan \& D. Lieberman (Eds.), To improve the academy: Vol. 17. Resources for faculty, instructional, and organizational development (pp. 245-262). Stillwater, OK: New Forums Press.

Brinko, K. T. (1997). The interactions of teaching improvement. In K. T. Brinko \& R. J. Menges (Eds.), Practically speaking: A sourcebook for instructional consultants in higher education (pp. 3-8). Stillwater, OK: New Forums Press.

Campbell, P. B., Jolly, E., Hoey, L., \& Perlman, L. K. (2002). Upping the numbers: Using research-based decision making to increase diversity in the quantitative disciplines. Newton, MA: Education Development Center, Inc.

Chesler, M. A. (1990). Action research in the voluntary sector: A case study of scholar-activist roles in health care settings. In S. A. Wheelan, E. A. Pepitone, \& V. Abt (Eds.), Advances in field theory (pp. 265-280). Newbury Park, CA: Sage.

Cook; C., Gerson, J., Godfrey, J., Kerner, N., Larsen-Freeman, D., Mullane, E., et al. (2002). Report of the Task Force on Testing and Training Prospective GSIs. Ann Arbor, MI: University of Michigan.

Cross, K. P., \& Steadman, M. H. (1996). Classroom research: Implementing the scholarship of tenching. San Francisco, CA: Josscy-Bass. 
Elden, M. (1981). Sharing the research work: Participative research and its role demands. In P. Reason \& J. Rowan (Eds.), Human inquiry: A sourcebook of new paradigm research (pp. 261-266). Chichester, England: John Wiley \& Sons.

Geltner, B. B. (1993, October). Collaborative action research: A critical component in the preparation of effective leaders and learners. Paper presented at the annual meeting of the University Council for Educational Administration, Houston, TX.

Gillespie, K. (2001, October). Marketplace reality and our dreams of the profession. Paper presented at the 26th annual conference of the Professional and Organizational Development Network in Higher Education, St. Louis, MO.

Gouldner, A. W. (1957, December). Cosmopolitans and locals: Toward an analysis of latent social roles. Administrative Science Quarterly, 2(3), 281-306.

Greenwood, D. J., \& Levin, M. (1998). Introduction to action research: Social research for social change. Thousand Oaks, CA: Sage.

Halstead, D. K. (1974). Statewide planning in higher education. Washington, DC: U.S. Government Printing Office.

Holstrom, E. I., Gaddy, C. D., Van Horne, V.V., \& Zimmerman, C. M. (1997). Best and brightest: Education and career paths of top science and engineering students. Washington, DC: Commission on Professionals in Science and Technology.

Israel, B. A., Schurman, S. J., \& Hugentobler, M. K. (1992, March). Conducting action research: Relationships between organization members and researchers. Journal of Applied Behavioral Science, 28(1), 74-101.

Krogh, L. (2001, March). Action research as action learning as action research as action learning... at multiple levels in adult education. Paper presented at the 4th annual conference of the Australian Vocational Education and Training Research Association, Adelaide, Australia.

Lewin, K. (1997). Resolving social conflicts. Washington, DC: American Psychological Association. (Original work published 1948)

Montgomery, S. M., \& Groat, L. N. (1998). Student learning styles and their implications for teaching (CRLT Occasional Paper No. 10). Ann Arbor, MI: Center for Research on Learning and Teaching, University of Michigan.

National Science Board. (2004). Science and engineering indicators, 2004 (NSB 04-01). Arlington, VA: National Science Foundation, Division of Science Resource Statistics.

National Science Foundation, Division of Science Resources Statistics. (2003). Women, minorities, and persons with disabilities in science and engineering: 2002 (NSF 03-312). Arlington, VA: Author. 
Nyquist, J. D., \& Wulff, D. H. (1988). Consultation using a research perspective. In E. C. Wadsworth, L. Hilsen, \& M. A. Shea (Eds.), A handbook for new practitioners (pp. 81-88). Stillwater, OK: New Forums Press.

Park, P. (1999, June). People, knowledge, and change in participatory research. Management Learning, 30(2), 141-157.

Polanyi, M., \& Cockburn, L. (2003, Summer). Opportunities and pitfalls of community-based research: A case study. Michigan Journal of Community Service Learning, 9(3), 16-25.

Reason, P. (1999, June). Integrating action and reflection through co-operative inquiry. Management Learning, 30(2), 207-226.

Schön, D. A. (1983). The reflective practitioner: How professionals think in action. New York, NY: Basic Books.

Schön, D. A. (1987). Educating the reflective practitioner. San Francisco, CA: JosseyBass.

Seldin, P. (1997). Using student feedback to improve teaching. In D. DeZure \& M. Kaplan (Eds.), To improve the academy: Vol. 16. Resources for faculty, instructional, and organizational development (pp. 335-345). Stillwater, OK: New Forums Press.

Selingo, J. (2005, October 14). U.S. spends billions to encourage math and science students, but it's unclear if programs work, report says. Retrieved June 16, 2006, from http://chronicle.com/daily/2005/10/2005101402n.htm

Seymour, E. (2001). Tracking the processes of change in US undergraduate education in science, mathematics, engineering and technology. Science Education, 86, 79-105.

Seymour, E., \& Hewitt, N. M. (1997). Talking about leaving: Why undergraduates lcave the sciences. Boulder, CO: Westview Press.

Seymour, E., with Melton, G., Wiese, D. J., \& Pedersen-Gallegos, L. (2005). Partners in innovation: Teaching assistants in college science courses. Lanham, MD: Rowman \& Littlefield.

Small, S. A. (1995, November). Action-oriented research: Models and methods. Journal of Marringe and the Family, 57(4), 941-955.

Sorcinelli, M. D., Austin, A. E., Eddy, P. L., \& Beach, A. L. (2006). Creating the future of faculty development: Learning from the past, understanding the present. Bolton, MA: Anker. 
St. John, E. P., McKinney, J., \& Tuttle, T. (in press). Using action inquiry to address critical challenges. In E. P. St. John \& M. Wilkerson (Eds.), New directions for institutional research: Improving academic success: Reframing persistence research. San Francisco, CA: Josscy-Bass.

Strand, K., Marullo, S., Cutforth, N., Stoecker, R., \& Donohue, P. (2003, Summer). Principles of best practice for community-based research. Michigan Journal of Community Service Learning, 9(3), 5-15.

Strenta, A. C., Elliot, R., Adair, R., Matier, M., \& Scott, J. (1994, October). Choosing and leaving science in highly selective institutions. Research in Higher Education, 35(5), 513-547.

Stringer, E. T. (1999). Action research (2nd ed.). Thousand Oaks, CA: Sage.

Tobias, S. (1990). They're not dumb, they're different: Stalking the second tier. Tucson, AZ: Research Corporation.

Wright, W. A., \& O’Neill, W. M. (1995). Teaching improvement practices: International perspectives. In W. A. Wright \& Associates, Teaching improvement practices: Successful strategies for higher education (pp. 1-57). Bolton, MA: Anker.

Xie, Y., \& Shauman, K. A. (2003). Women in science: Career processes and outcomes. Cambridge, MA: Harvard University Press.

Zuber-Skerritt, O. (1992). Action research in higher education: Examples and reflections. London, England: Kogan Page.

Zuelke, D. C., \& Nichols, T. M. (1995, November). Collaborative school climate action research for school improvement: Part II. Paper presented at the annual meeting of the Mid-South Education Research Association, Biloxi, MS. 